\title{
Pelestarian Habitat Penyu Dari Ancaman Kepunahan Di Turtle Conservation And Education Center (TCEC), Bali
}

\author{
Raden Ario, Edi Wibowo, Ibnu Pratikto, Surya Fajar \\ Departement IImu Kelautan, Fakultas Perikanan dan IImu Kelautan, Universitas Diponegoro \\ JI. Prof. Soedarto, SH. Kampus UNDIP Tembalang, Semarang 50275 \\ Email: ario_1960@yahoo.com
}

\begin{abstract}
Abstrak
Penyu merupakan salah satu fauna yang dilindungi karena populasinya yang terancam punah. Reptil laut ini mampu bermigrasi dalam jarak yang sangat jauh di sepanjang kawasan Samudera Hindia, Samudera Pasifik, dan Asia Tenggara. Di dunia ada 7 jenis penyu dan 6 diantaranya terdapat di Indonesia. Konservasi merupakan salah satu kegiatan yang diharapkan dapat mencegah punahnya habitat penyu karena predator alami maupun manusia. Penelitian dilaksanakan mulai tanggal 4 - 24 Agustus 2014 dan bertempat di Turtle Conservation and Education Center (TCEC), Denpasar Selatan, Bali. Penelitian ini bertujuan untuk mengetahui teknik konservasi dan persentase keberhasilan penetasan telur penyu di TCEC, Bali. Metode yang digunakan dalam penelitian ini adalah metode wawancara, observasi atau pengamatan secara langsung yang dilakukan di lapangan, dan metode pengukuran suhu sarang semi alami. Pengukuran suhu dilakukan untuk mengetahui jenis kelamin dari tukik yang menetas. Hasil penelitian menunjukan bahwa lokasi penangkaran penyu berada di kawasan yang kurang strategis karena letaknya terlalu jauh dari air laut sehingga suhu serta kelembabannya tidak dapat stabil. Kadar air merupakan faktor penting dalam pertumbuhan embrio dan penetasan telur. Hal ini akan menyebabkan penurunan persentase penetasan telur penyu. TCEC didirikan sebagai tempat edukasi konservasi penyu, pelestarian penyu, dan penyedia penyu untuk upacara adat di Bali serta mengurangi perdagangan baik daging, cangkang ataupun telur penyu.
\end{abstract}

Kata Kunci: Pelestarian, Penyu, TCEC Bali

\section{PENDAHULUAN}

Indonesia merupakan Negara Kepulauan terbesar di dunia dengan jumlah pulau lebih dari 17.500 di sepanjang ekuator dan lebih dari 360 juta hektar area laut. Terhampar diantara isothermal $20^{\circ} \mathrm{LU} / \mathrm{LS}$ merupakan lokasi yang baik bagi pertumbuhan terumbu karang, rumput laut dan keanekaragaman hayati termasuk penyu laut (Limpus dan McLachian, 1996).

Ada 7 jenis penyu di dunia dan 6 diantaranya terdapat di Indonesia. Jenis penyu yang ada di Indonesia adalah Penyu Hijau (Chelonia mydas), Penyu Sisik (Eretmochelys imbricata), Penyu Lekang (Lepidochelys olivacea), Penyu Belimbing (Dermochelys coriacea), Penyu Pipih (Natator depressus) dan Penyu Tempayan (Caretta caretta).
Penyu telah mengalami penurunan jumlah populasi dalam jangka waktu terakhir ini bahkan beberapa spesies terancam kepunahan. Di alam, penyupenyu yang baru menetas menghadapi ancaman kematian dari hewan-hewan seperti kepiting, burung, dan reptilia lainnya seperti biawak. Ancaman yang paling besar bagi penyu di Indonesia, seperti juga halnya di seluruh dunia, adalah manusia. Pembangunan daerah pesisir yang berlebihan telah mengurangi habitat penyu untuk bersarang. Penangkapan penyu untuk diambil telur, daging, kulit, dan cangkangnya telah membuat populasi penyu berkurang. Semua penyu menurut Sukresno (1997) telah terdaftar dalam Daftar Apendik I CITIES (Convension on International Trade of Endangered Species). Konvensi ini melarang semua perdagangan internasional atas semua produk yang 
berasal dari penyu, baik itu berupa telur, daging, maupun cangkangnya.

Berdasarkan peraturan perundangundangan jenis Penyu Belimbing dilindungi berdasarkan SK Menteri Pertanian No.327/Kpts/Um/5/1978; Penyu Tempayan dan Lekang dilindungi berdasarkan SK Menteri Pertanian No.716/Kpts/Um/10/1980; Penyu Sisik dan Penyu Pipih dilindungi berdasarkan SK Menteri Kehutanan No.882/Kpts-II/1992, dan Penyu Hijau yang termasuk dalam 6 jenis penyu yang dilindungi berdasarkan PP No.7/1999 tentang pengawetan tumbuhan dan satwa.

Konservasi merupakan salah satu kegiatan yang diharapkan dapat mencegah punahnya habitat penyu, mencegah adanya pemanfaatan penyu demi kepentingan komersial seperti penjualan telur, daging, maupun cangkang dan dapat menjadi sarana berbagi ilmu atau edukasi kepada masyarakat secara luas tentang pentingnya konservasi penyu demi menjaga habitat penyu di Indonesia agar tidak punah.

Adapun tujuan dari penelitian ini adalah untuk mengetahui segala macam kegiatan mengenai konservasi yang ada di TCEC, serta menyebar luaskan informasi terkait perlindungan dan pelestarian penyu laut kepada masyarakat secara luas. Sedangkan manfaat dari penelitian ini diharapkan dapat memberikan informasi pada masyarakat luas dan instansi terkait dalam melaksanakan pengelolaan dan perlindungan habitat penyu di kawasan Turtle Conservation and Education Center (TCEC), Bali sehingga dapat mendukung program pelestarian habitat penyu di Indonesia.

\section{MATERI DAN METODE}

Penelitian dilakukan dalam kurun waktu mulai pada tanggal 4 Agustus 2014 hingga 24 Agustus 2014 dengan lokasi pengamatan di Turtle Conservation and Education Center (TCEC), Denpasar Selatan, Bali. Materi yang digunakan dalam penelitian ini adalah mengenai konservasi penyu yang ada di Turtle Conservation and Education Center (TCEC). Pengambilan data diperoleh dari pengukuran panjang, lebar, dan kemiringan pantai, suhu dan kelembaban sarang.

Peralatan yang digunakan dalam penelitian ini antara lain: peta lokasi penelitian, GPS (Global Positioning System), buku identifikasi tumbuhan pesisir pantai, thermometer, rool meter, tongkat berskala, kantong sampel, kamera digital, dan alat tulis.

Metode yang digunakan dalam penelitian ini adalah metode survey deskriptip. Menurut Nasir (1983), metode ini untuk membuat gambaran secara sistematis, faktual, dan akurat mengenai fakta-fakta, sifat-sifat serta hubungan antara faktor-faktor lingkungan atau fenomena yang dipelajari. Pengumpulan data dilakukan dengan cara wawancara, observasi langsung di lapangan, dan pengukuran suhu sarang semi alami. Metode wawancara dengan pengelola instansi terkait, observasi atau pengamatan secara langsung kegiatan yang dilakukan di lapangan untuk mengetahui kegiatan apa sajakah yang ada di kawasan konservasi. Pengukuran suhu pada kolam pembesaran dan sarang semi alami dilakukan mulai dari hari ke 4 hingga hari ke 15 dalam rentan waktu yang sudah ditentukan pada pukul 08.00 WITA. Pengukuran suhu menggunakan thermometer yang dimasukkan ke dalam sarang semi alami lalu dicatat hasil pengukurannya. Setelah itu mencatat jumlah telur pada sarang semi alami dan mendata ada berapa telur yang berhasil menetas maupun gagal menetas.

\section{HASIL DAN PEMBAHASAN}

Jumlah kolam pembesaran di TCEC berjumlah 15 kolam dengan ukuran yang sama. Sebanyak 12 kolam berisi Tukik dengan jumlah Tukik terbanyak pada kolam ke 6 dan 7 yaitu 350 tukik. Kolam 1 hingga 4 terisi Tukik dengan jumlah yang paling sedikit yaitu 200 ekor/kolam. 
Sebanyak 3 kolam terisi Penyu dengan jumlah penyu terbanyak kolam ke 9 dengan 5 ekor Penyu, dan paling sedikit pada kolam ke 5 dengan 2 ekor Penyu dan selengkapnya dapat dilihat pada Tabel 1.

Konservasi merupakan upaya yang sangat penting demi kelestarian penyu laut itu sendiri dari ancaman kepunahan yang disebabkan oleh berbagai faktor ancaman seperti perburuan liar terhadap telur maupun cangkang dari penyu laut, serta dari predator alami seperti semut, biawak, dan lain-lain. Di TCEC terdapat 3 spesies penyu yaitu Penyu Hijau (Chelonia mydas), Penyu Sisik (Eretmochelys imbricata), dan Penyu Lekang (Lepidochelys olivacea). Sementara spesies tukik yang ada di TCEC yaitu

Tabel 1. Jumlah Tukik dan Penyu pada Kolam Pembesaran di TCEC

\begin{tabular}{ccc}
\hline Kolam Pembesaran & $\begin{array}{c}\text { Jumlah Tukik } \\
\text { (ekor) }\end{array}$ & $\begin{array}{c}\text { Jumlah Penyu } \\
\text { (ekor) }\end{array}$ \\
\hline 1 & 200 & - \\
2 & 200 & - \\
3 & 200 & - \\
4 & 200 & - \\
5 & - & 2 \\
6 & 350 & - \\
7 & 350 & - \\
8 & 329 & - \\
9 & - & 5 \\
10 & - & 3 \\
11 & 250 & - \\
12 & 250 & - \\
13 & 250 & - \\
14 & 250 & - \\
15 & 250 & - \\
\hline
\end{tabular}

Tabel 2. Data Kelahiran dan Kematian Tukik pada Sarang Semi Alami di TCEC

\begin{tabular}{cccccc}
\hline Hari ke & Tanggal & $\begin{array}{c}\text { Suhu Sarang } \\
{ }^{0} \text { C }\end{array}$ & Jumlah Telur & Menetas & Gagal Menetas \\
\hline 1 & $06 / 08 / 2014$ & - & - & - & - \\
2 & $07 / 08 / 2014$ & - & - & - & - \\
3 & $08 / 08 / 2014$ & - & - & - & - \\
4 & $09 / 08 / 2014$ & $30-31$ & 100 & 70 & 30 \\
5 & $10 / 08 / 2014$ & $28-31$ & 100 & 59 & 41 \\
6 & $11 / 08 / 2014$ & $31-32$ & 100 & 25 & 75 \\
7 & $12 / 08 / 2014$ & $30-31$ & - & - & - \\
8 & $13 / 08 / 2014$ & $30-31$ & 100 & 49 & 51 \\
9 & $14 / 08 / 2014$ & $30-31$ & 100 & 72 & 28 \\
10 & $15 / 08 / 2014$ & $29-30$ & - & - & - \\
11 & $16 / 08 / 2014$ & $29-30$ & - & - & - \\
12 & $17 / 08 / 2014$ & $29-30$ & 100 & 62 & 38 \\
13 & $18 / 08 / 2014$ & $28-31$ & 100 & 67 & 33 \\
14 & $19 / 08 / 2014$ & $30-31$ & 100 & 68 & 32 \\
15 & $20 / 08 / 2014$ & $30-31$ & - & - & - \\
\hline
\end{tabular}



spesies Lekang (Lepidochelys olivacea). Priyono (1988), menyatakan bahwa struktur ukuran penyu dikelompokkan kedalam empat kategori yaitu: (1) Tukik muda: baru dilahirkan/menetas dan masih terlihat tali pusarnya, hingga minggu pertama. (2) Tukik: sisa tali pusarnya sudah hilang dan panjang karapas $\pm 40 \mathrm{~cm}$. (3) Muda: tukik belum matang kelamin (panjang karapas sekitar 40-80 cm). (4) Dewasa: matang kelamin atau dewasa kelamin, panjang karapas lebih dari $80 \mathrm{~cm}$ (Ukuran minimal betina sekitar $80 \mathrm{~cm}$ ).

Penyu merupakan hewan pemakan segala (Omnivora). Setiap jenis penyu memiliki makanan yang spesifik. Penyu memiliki bentuk mulut dan paruh yang khusus untuk membantu mendapatkan makanannya. Penyu Sisik memiliki bentuk kepala dan paruh yang meruncing untuk memudahkan mencari makanan di terumbu karang. Penyu Lekang merupakan salah satu penyu yang bersifat karnivora, dan berparuh kuat dan besar untuk memangsa Ikan, ubur-ubur, cumi-cumi, bintang laut, kerang, kima, kepiting dan udang. Sedangkan Rebel (1974) menyatakan bahwa Penyu Hijau adalah satu-satunya jenis penyu yang diketahui cenderung herbivora. pemangsa alga dan lamun

Hasil wawancara dengan pengelola TCEC, diketahui keberadaan penyu memang banyak ditemukan didaerah pulau Serangan, Denpasar Selatan, Bali. Pulau Serangan merupakan habitat peneluran Penyu Lekang itu sendiri. Namun seiring berjalannya waktu banyak masyarakat yang mulai mengkonsumsi daging ataupun telur penyu. Daging diolah menjadi sate yang dijual secara bebas. Bahkan dalam upacara adat dibeberapa daerah di Bali menggunakan penyu laut ini sebagai simbol upacara dan dibunuh. Pulau Bali pernah mendapat banyak kecaman dari masyarakat diluar Bali bahkan diluar negeri dan pihak-pihak yang mengatas namakan perlindungan hewan punah karena tindakan upacara di Bali yang banyak menggunakan penyu. Namun untuk sekarang ini sudah jarang upacaraupacara adat di Bali yang menggunakan penyu, jikalau ada itu harus dibatasi jumlah penyu yang digunakan serta usia penyu tersebut. Langkah ini dilakukan demi menjaga kelestarian penyu laut itu sendiri.

Didirikannya Turtle Conservation and Education Center (TCEC) berfungsi sebagai tempat konservasi penyu, tempat penetasan semi alami dari telur-telur penyu yang diambil dari sarang alaminya dipinggir pantai agar telur tersebut dapat menetas dengan selamat tanpa harus terganggu oleh predator ataupun manusia. Selain itu TCEC juga sebagai tempat pembesaran tukik-tukik Penyu Lekang yang nantinya dilepas ke laut jika umurnya sudah kurang lebih 3 bulan.

Langkah ini diambil sebagai solusi agar masyarakat tak mengambil penyu langsung dari laut demi terjaganya kelestarian habitat penyu. Penyu yang disediakan untuk upacara adat berumur satu tahun lebih dan jumlahnya juga dibatasi. TCEC juga dijadikan sarana pendidikan dan dijadikan sebagai tempat wisata agar masyarakat lokal maupun turis asing dapat mengenal lebih dekat tentang penyu serta diharapkan timbulnya kesadaran untuk menjaga kelestarian penyu laut dari ancaman kepunahan. Ada kegiatan yang dinamakan "Mengadopsi tukik" dimana kegiatan ini ditujukan kepada turis yang ingin melepas tukik ke laut dari pinggir pantai. Sumbangan uang dari para turis dalam kegiatan "adopsi" inilah yang dijadikan sebagai penghasilan untuk membeli pakan tukik, dan lain-lain. Sedangkan para turis (lokal dan asing) juga mendapat sertifikat sebagai volunteer dari TCEC. Kerjasama TCEC dengan WWF Indonesia berada dibawah naungan Balai Konservasi Sumber Daya Alam (BKSDA) Denpasar, Bali.

Jumlah tukik dan penyu pada kolam pembesaran di TCEC (Tabell) berjumlah 15 kolam, dimana 12 kolam berisi tukik dan 3 kolam berisi penyu. Jumlah tukik terbanyak pada kolam ke 6 dan 7 yaitu 350 ekor tukik dan kolam 1 hingga 4 terisi sejumlah tukik yang paling sedikit yaitu 200 ekor tukik. Sedang 3 kolam terisi oleh 
penyu dengan jumlah penyu terbanyak ada pada kolam ke 9 dengan 5 ekor dan paling sedikit 2 ekor pada kolam 5. Hasil pendataan individual sebelumnya pada tahun 2013, menurut Bapak Griye selaku pembimbing lapangan dan pengelola TCEC diketahui bahwa jumlah tukik dan penyu pada kolam pembesaran jumlahnya lebih sedikit dibandingkan tahun 2014. Data dari tabel diatas adalah jumlah tukik dan penyu yang baik untuk bertahan hidup dan mengurangi angka kematian akibat penuhnya kolam oleh tukik maupun penyu. Hal utama yang harus diperhatikan pada pemeliharaan tukik adalah sirkulasi air. Sirkulasi air yang teratur menyebabkan sisa makanan dan sekresi tukik tereduksi secara terusmenerus. Selain itu mikroorganisme penyebab penyakit kulit pada tukik menjadi tidak mudah berkembang (Naulita, 1990).

Sistem Pemeliharan harus memenuhi syarat ekologis. Selain pengadaan sirkulasi air, luas tempat pemeliharaan juga mendapat perhatian khusus. Hal ini bertujuan memberikan ruang gerak yang luas bagi tukik karena tukik merupakan hewan yang aktif bergerak (Nuitja, 1992). Kedalaman air media pemeliharaan juga turut menentukan pertumbuhan tukik selama pemeliharaan. Dinyatakan dalam Nontji (2005), bahwa pada hari-hari pertamanya di air, tukik belum bisa menyelam karena dalam tubuhnya masih kuning telur yang belum tercerna seluruhnya. Keberadaan kuning telur tersebut menyebabkan berat jenis tubuh tukik menjadi rendah dan hanya dapat berenang di permukaan.

Kualitas air yang digunakan untuk media hidup tukik yang dipelihara juga memerlukan perhatian khusus. Parameter yang harus diperhatikan dalam menjaga kualitas air media antara lain $\mathrm{pH}$, salinitas, suhu dan oksigen terlarut (DO). Air laut mempunyai kisaran $\mathrm{pH}$ yang relatif stabil karena memiliki kemampuan sebagai penyangga yang tinggi (Naulita, 1990). Salinitas mempengaruhi aktifitas biologis yaitu pada proses osmoregulasi. Penyu merupakan hewan poikilotermal, suhu tubuh mengikuti suhu lingkungan sampai pada batas tertentu (Jackson, 1979).
Data kelahiran dan kematian tukik pada sarang semi alami serta dilakukannya pengukuran suhu di sarang semi alami yang dimulai dari hari ke 4 hingga hari ke 15 dalam rentan waktu yang sudah ditentukan pada pukul 08.00 WITA (Tabel 2). Diketahui berapa jumlah tukik yang dapat menetas dan gagal menetas pada sarang semi alami dan pengukuran suhu dilakukan untuk mengetahui jenis kelamin dari tukik yang menetas. Pada hari 1 hingga ke 3 tidak dilakukan pendataan. Telur pada setiap sarang berjumlah 100 butir dengan pengukuran suhu yang didapat berkisar dari $28^{\circ} \mathrm{C}$ hingga $32^{\circ} \mathrm{C}$.

Jumlah telur menetas paling banyak didapatkan pada hari ke 9 yaitu 72 butir telur dan jumlah telur yang gagal menetas paling banyak didapatkan pada hari ke 6 yaitu 75 butir telur. Faktor-faktor yang mempengaruhi telur dapat menetas dengan jumlah yang banyak maupun gagal menetas karena pengaruh pasir yang digunakan, pergantian pasir yang digunakan, dan kedalaman sarang semi alami tersebut. Pada hari ke $7,10,11$, dan 15 tidak ada telur yang menetas maupun gagal menetas. Menurut Limpus (1979), dari ratusan butir telur yang dikeluarkan oleh seekor penyu betina, paling banyak hanya belasan penyu yang berhasil sampai ke laut kembali dan tumbuh dewasa. Itupun tidak memperhitungkan faktor perburuan oleh manusia dan predator alaminya seperti kepiting, burung dan tikus di pantai, serta ikan-ikan besar begitu tukik tersebut menyentuh perairan dalam.

Setelah selesai masa bertelur induk akan kembali ke laut, masa pengeraman telur penyu adalah sekitar 45-60 hari dan suhu dalam sarang akan menentukan jenis kelamin dari tukik itu sendiri, jadi semakin rendah suhu yang berada dalam sarang tersebut, maka akan menghasilkan lebih banyak tukik jantan dan begitupun sebaliknya bila suhu sarang tersebut tinggi maka tukik yang banyak dihasilkan adalah berkelamin betina. Tukik yang baru menetas akan mencari jalan ke luar kepermukaan sarang selama 3-7 hari, kemudian tukik akan ke luar dari sarang pada saat malam hari karena suhu lebih 
dingin dan ancaman dari pemangsa sangat sedikit dan tukik akan langsung menuju ke lautan. Pada saat mencapai laut, tukik menggunakan berbagai kombinasi petunjuk (arah gelombang, arus dan medan magnet) untuk orientasi ke daerah lepas pantai yang lebih dalam. Kegiatan tukik melewati pantai dan berenang menjauh adalah upaya untuk merekam petunjuk-petunjuk yang diperlukan untuk menemukan jalan pulang saat mereka akan kawin, disebut dengan imprinting process. Saat tukik sudah berada di laut diduga memasuki kawasan di mana arus-arus laut bertemu, tukik-tukik tersebut menggunakan rumputrumput laut yang mengapung. Tukik jarang terlihat lagi hingga karapasnya mencapai ukuran $20-40 \mathrm{~cm}$ dengan usia sekitar 5-10 tahun setelah menetas. Tukik biasanya bersembunyi disekitar wilayah terumbu karang dan lamun (Dinas Kelautan Perikanan, 2009). Pada saat tukik yang telah menjadi dewasa berenang kembali ke ruaya pakan di pesisir dan tinggal di daerah tersebut sampai siap memijah dan saat itu pula siklus hidup penyu dimulai lagi. Masa tukik-tukik menghilang disebut sebagai tahun-tahun hilang (the lost years), yang ternyata saat itu tukik berlindung dan mencari makan di daerah rumput laut jenis Sargassum sp. Dinyatakan dalam Dinas Kelautan Perikanan (2009) bahwa dari 1000 ekor tukik yang ke laut hanya ada satu yang akan bertahan sampai dewasa.

Konservasi penyu yang telah dilakukan oleh TCEC berdampak positip dalam perubahan pola pikir masyarakat di pulau Serangan maupun di daerah Bali lainnya untuk mengembangkan upaya pelestarian penyu dengan cara mendirikan posko-posko pengamatan di sepanjang pinggir pantai yang berguna untuk mengamati jika ada penyu yang naik ke daaratan untuk bertelur dan menyelamatkan telurnya dari predator alami serta manusia yang ingin mengambilnya. Turut serta menyebar luaskan tentang pentingnya upaya pelestarian penyu agar pantai-pantai di Bali tetap bisa jadi tempat bagi penyu tersebut untuk naik ke daratan lalu bertelur serta sosialisasi yang dilakukan dengan anak-anak sekolah serta mahasiswa dan mahasiswi tentang apa itu konservasi penyu, pentingnya dilakukan upaya pelestarian agar habitat penyu tetap terjaga dengan cara jangan membuang sampah plastik ke laut karena bisa termakan oleh penyu, jangan memakan daging penyu yang menjadi hidangan di restoran-restoran mewah di Bali dan mengurangi upaya penangkapan penyu di alam untuk dijadikan bahan dalam upacara adat di Bali.

\section{KESIMPULAN}

Konservasi penyu di TCEC memiliki kegiatan seperti penetasan telur penyu di sarang semi alami, pembesaran tukik di kolam pembesaran, mengadopsi tukik untuk dilepaskan ke laut, serta sebagai sarana edukasi. Pelestarian penyu saat ini sudah lebih baik dari sebelumnya karena sekarang masyarakat sudah sadar untuk tidak menjual cangkang penyu, tidak memburu penyu di alamnya lagi sebagai bahan untuk upacara adat, dan tidak mengkonsumsi daging dan telur penyu.

\section{SARAN}

Informasi tentang konservasi penyu laut harus disebar luaskan agar seluruh masyarakat dapat mengetahui manfaat dari konservasi penyu laut itu sendiri. Segala bentuk perdagangan yang menyangkut penyu laut baik daging ataupun cangkangnya harus dihentikan dan penyu laut harus dilindungi oleh undang-undang khusus yang menjaga agar tidak punahnya hewan ini.

\section{DAFTAR PUSTAKA}

Departemen Kehutanan. 1999. Peraturan Pemerintah Republik Indonesia Nomor 7 tahun 1999 tentang Pemanfaatan Jenis Tumbuhan dan Satwa. Departemen Kehutanan Indonesia. Jakarta.

Dinas Kelautan Perikanan. 2009. Laut, Pesisir dan Pulau-pulau Kecil. Departemen Kelautan dan Perikanan, Jakarta. Jakarta. HIm 96. 
Jackson, D.C. 1979. Respiration, in turtle prespective and research. M. Harles and $\mathrm{H}$. Morlock, (editor). A Wiley Interscience Publication. New York. p: 165-191.

Limpus, C.J. and McLachlan, N. 1996. The conservation status of the leatherback turtle, Dermochelys coriacea, in Australia. In R. James, ed. Proc. Marine Turtle Conservation Workshop, pp. 6872. Canberra, Australia, Australian National Parks and Wildlife Service.

Limpus, C J. 1970. Notes Rates Growth, Marine Conservation Rates of Wild Turtles. Marine Turtles News Latter. Australia.

Nasir, M. 1988. Metode Penelitian. Ghalia. Jakarta. $90 \mathrm{hlm}$.

Nontji, Anugerah., 2005. Laut Nusantara. Cetakan Keempat. Djambatan. Jakarta. $372 \mathrm{hlm}$.

Naulita, Y. 1990. Telaah laju pertumbuhan tukik Penyu Hijau (Chelonia mydas) pada pemberian makan yang berbeda. Jurusan Managemen
Sumberdaya Perikanan, Fakultas Perikanan IPB, 92 hal.

Nuitja, I.N.S. 1992. Biologi dan Ekologi Pelestarian Penyu Laut.IPB Press. Bogor. 128 hal.

Priyono, A. 1988. Penyu dan kura-kura (ordo Chelonia).Jurusan Konservasi Sumberdaya Hutan Fakultas Kehutanan Institut Pertanian Bogor. Bogor. 51 hal.

Rebel, T.P. 1974. SeaTurtle and The Turtle Industry of The West Indies, Florida, and The Gulf of Mexico. University of Miamy Press. Coral Gables. Florida. $134 \mathrm{pp}$.

Sukresno, S.A. 1997. Pemanfaatan Penyu Laut di Indonesia. Makalah Seminar Penelitian dan Pengelolaan Penyu di Indonesia. Jember-Indonesia.

Yayasan Alam Lestari (YAL). 2000. Mengenal Penyu. Yayasan Alam Lestari dan Keidanren Nature Conservation Fund (KNCF) Jepang. 81 hlm. 